\title{
Imaging of micro-organisms on topsoil particles collected from different landscape in the Gobi Desert
}

\author{
Morine Kuribayashi ${ }^{1}$, Keiichi Kawano ${ }^{2}$, Yuta Demura $^{1}$, Kenji Baba $^{1}$, Yuki Sofue ${ }^{3}$, Purevsuren Tsedendamba ${ }^{1}$, Tamaki \\ Matsumoto $^{1}$, Katsuro Hagiwara ${ }^{4}$, Olaf Karthaus $^{2},{\text { Kenji } \text { Kai }^{5}, \text { Buho Hoshino }}^{1 *}$ \\ ${ }^{1}$ Department of Environmental Sciences, Rakuno Gakuen University, Ebetsu 069-8501, Japan \\ ${ }^{2}$ Nanotechnology Platform, MEXT, Japan, Chitose Institute of Science and Technology, Chitose 066-8655, Japan \\ ${ }^{3}$ The Graduate School of Sciences, Chiba University, Chiba 263-8522, Japan \\ ${ }^{4}$ School of Veterinary Medicine, Rakuno Gakuen University, Ebetsu, 069-8501, Japan \\ ${ }^{5}$ College of Education, Ibaraki University, 2-1-1, Bunkyo, Mito, 310-8512, Japan
}

\begin{abstract}
This study shows the results of field experiments of soil particles saltation and laboratory experiments of imaging of the surface structure of dust particles. In the Gobi area, dust occurs when the wind speed at ground level exceeds $7 \mathrm{~m} / \mathrm{s}$. It has been reported that bacteria are attached to dust, but the details of its attachment are unknown. It is also expected that these bacteria will fly at the time of occurrence of dust, and fundamental research is important to clarify the relationship between dust components and bacteria.
\end{abstract}

\section{BACKGROUND OF THE STUDY}

The Gobi desert of Mongolia is the main source region of Asian dust storms. Due to climatic factors and artificial development such as overgrazing and open pitting, the area has unprecedented serious environmental problems [1-4].

The destroyed topsoil is exposed to wind, making dust more likely to occur than in the past. Also, there is the possibility that various microorganisms are attached to the soil particles [5-9]. Dust storms in arid and semiarid areas are not only effected by weather conditions such as strong winds at the time of occurrence, but also effected by the surface condition (for example, conditions of soil dry condition, vegetation, snow cover etc.). Fig. 1 (a, b) shows the monthly average wind speed, the number of dust occurrence and the vegetation status around our study area of Sainshand (the capital of Dornogovi Province in Mongolia located in the eastern Gobi desert steppe). As shown in Fig. 1, the main dust season is in spring when the wind speed is highest and the ground surface is almost bare (indicated by a NDVI value close to zero).

Experiments on dust particles mobilization are very important to determine the threshold wind speed velocity for dust entrainment in the truly grand roughness and moisture conditions of field. It has been reported that bacteria are attached to dust, but the details of its attachment are unknown. In this paper, E. coli known as bacteria present in the arid environment (or grazing area) and similar in size to other bacteria was used as model bacteria.
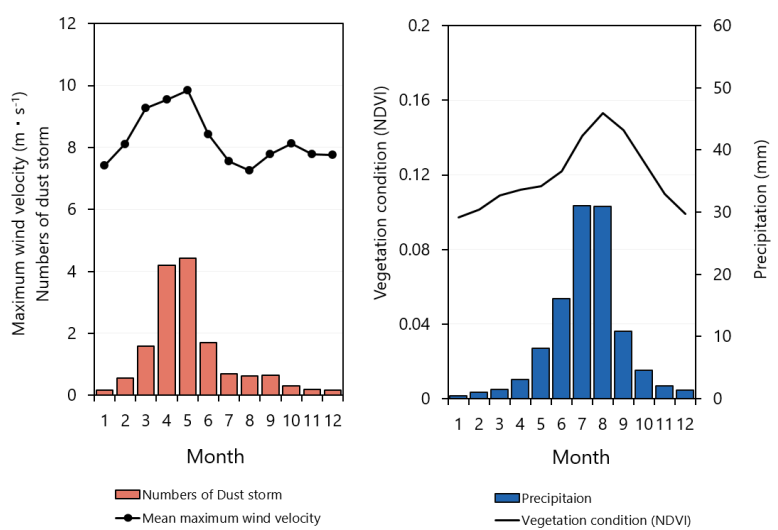

Fig. 1. Monthly means of numbers of dust storm (left), maximum wind velocity, and precipitation and vegetation condition (NDVI) (right) in the study area.

In this study, we used multiple precision equipment's, such as a field emission-type scanning electron microscope (FE-SEM, C JSM-7800F, JEOL Ltd.), a fluorescence microscope (BX 51, C) Olympus Corporation) and a Raman image microscope (In Via, C Renishaw Ltd.), to identify microorganisms attached to the soil samples from the Mongolian Gobi desert. We examine the collected soil samples and aimed at imaging of microorganisms attached to the top soil surface. In order to investigate the relationship between wind speed and saltation of soil particles at the field site, we used a handmade equipment.

\footnotetext{
* Corresponding author: aosier@rakuno.ac.jp
} 


\section{Methodology}

\subsection{Field Experiments}

The study area located in Sainshand City of Mongolian Dornogovi Province is shown in Fig. 2. As topographical features, the upper wind region has a slightly higher and the lower wind region has a slightly lower altitude, and the entire topography is a moderate basin with an altitude of $800 \mathrm{~m}$ to $1200 \mathrm{~m}$.

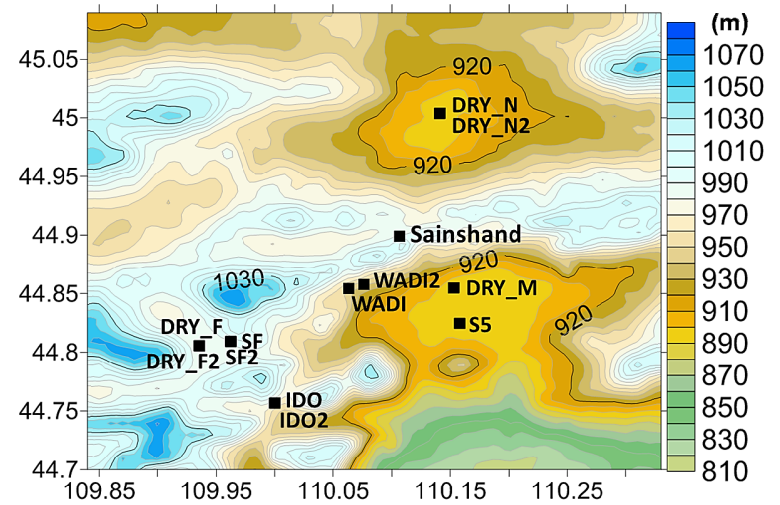

Fig. 2. Topography and measurement points of the study site (where, DR-Dry Lake Beds; WAD-Wadi (Dry River Basin); and IDO-Well; ordinate: latitude; abscissas: longitude).

Dust particle saltation experiments (field experiment of blowing off the ground surface with a blower) were conducted at a total of 10 sites in the desert area, dry lake, and dry lake area. The condition of field experiment shows in Table 1. The measured dust concentration was measured for each of two particle sizes of $1 \mu \mathrm{m}<3 \mu \mathrm{m}$ and $3 \mu \mathrm{m}<5 \mu \mathrm{m}$. For measurement of the number of dust saltation, a handheld particle counter Model 3886 manufactured by CKANOMAX Co., Ltd. was used. Dimensions of measuring equipment and photographs of saltation experiments are shown in Fig. 3. In order to minimize the influence from the outside air, the air inlet of the blower was installed on the windward side, and the blower and the measurement point were sealed except for the air inlet and the air outlet. In the measurement method, an artificially generated wind is blown onto the ground surface stepwise by a blower, and the concentration of the saltation dust particles is measured. Here, stepwise means five stages of rotation speeds of the blower: 1200, 1400, 1600, 1800, $1900 \mathrm{rpm}$ (revolution per minute). Air was blown for one minute at each stage, and dust particles saltation at each stage were measured. In addition, the wind speed for each rotation speed of the blower was measured. By doing this, we examined the difference in the number of dust saltation for each wind speed in the desert area and dry lake.
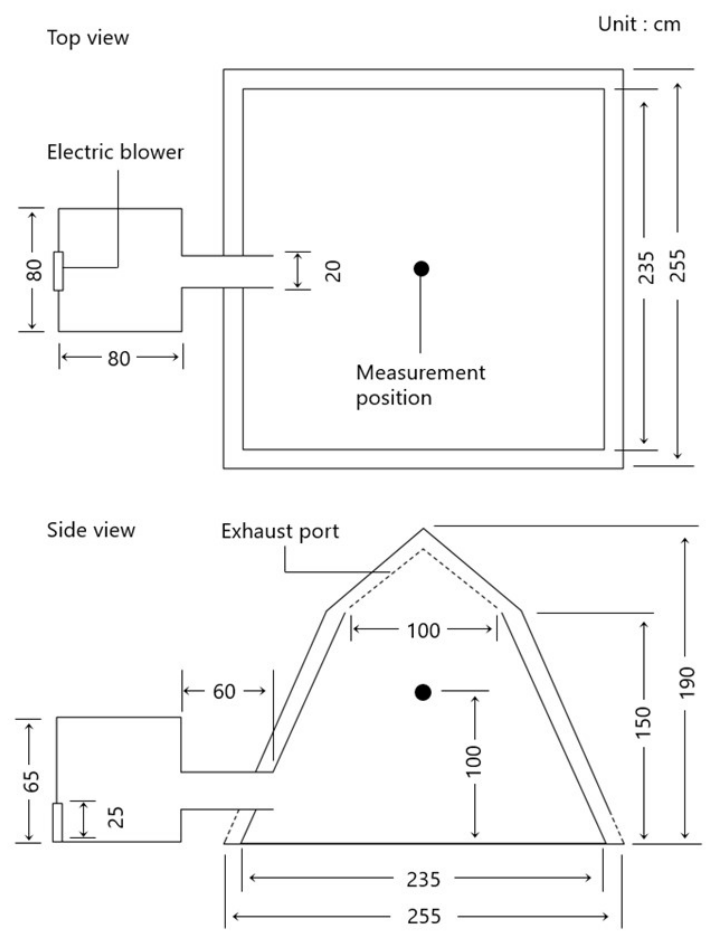

Fig. 3. Equipment of the wind tunnel test.

Table 1. The condition of fiels experiment of soil particles saltations.

\begin{tabular}{|c|c|c|c|c|c|c|}
\hline Study sites & Day & $\mathbf{T}$ & $\mathbf{C L}$ & $\begin{array}{l}\text { WS } \\
(\mathbf{m} / \mathbf{s})\end{array}$ & $\begin{array}{l}\text { GT } \\
\left({ }^{\mathbf{C}} \mathbf{C}\right)\end{array}$ & $\begin{array}{l}\text { SM } \\
\mathbf{( \% )}\end{array}$ \\
\hline DRY_M & 25 & $13: 13$ & 1 & - & 37.5 & 7.1 \\
\hline S5 & 25 & $15: 29$ & 2 & 0.3 & 23.6 & 3.6 \\
\hline SF & 26 & $12: 03$ & 0 & 2.6 & 33.4 & 5 \\
\hline SF2 & 26 & $12: 50$ & 0 & 1.2 & 40.8 & 6.3 \\
\hline DRY_F & 27 & $11: 17$ & 1 & 4.4 & 31.6 & 3.7 \\
\hline DRY_F2 & 27 & $11: 58$ & 3 & 4.4 & 32.3 & 2.9 \\
\hline IDO & 27 & $13: 38$ & 2 & 5.1 & 41.1 & 2.4 \\
\hline IDO2 & 27 & $14: 53$ & 3 & 5 & 36.4 & 4.6 \\
\hline WADI & 27 & $16: 21$ & 3 & 8.1 & 29.1 & 0.9 \\
\hline DRY_N & 28 & $11: 58$ & 2 & 1.3 & 39.6 & 8.7 \\
\hline DRY_N2 & 28 & $12: 37$ & 3 & 3 & 41.8 & 7.8 \\
\hline WADI2 & 28 & $15: 30$ & 3 & 2.5 & 38.5 & 1.7 \\
\hline
\end{tabular}

Where, Day-measurement days of April 2018; T-Local time; CL-Cloud/10; WS-wind speed (m/s); GT- Ground temperature (C); SM-Soil moisture (\%). 


\subsection{Laboratory Experiments}

It is expected that these bacteria will fly at the time of dust generation, and Escherichia coli (DH $5 \alpha$ ) was used as a model of bacteria in this area to be domesticated grazed. E. coli suspended in phosphate buffer (PBS) were co-cultured with sea sand as a positive control. Soil particles from Mongolia were sterilized in an autoclave at $120^{\circ} \mathrm{C}$. Samples were prepared by immobilizing the sand specimen on a sticky carbon tape on a mounting stage $(1 \mathrm{~cm}$ in diameter $)$. First, the specimen was observed in a fluorescence microscope and individual sand grains were identified. Next, the same particles were imaged with the FE-SEM, and energy dispersive spectroscopy (EDS) imaging was performed for mapping of the chemical elements in the samples. We also aimed to identify organic matter using Raman imaging.

Used equipment's: a. Field emission scanning electron microscope (JSM-7800F); b. Fluorescent microscope (BX 51); c. Raman imaging (RENISHAW: inVia).

\section{Results and Discussion}

\subsection{Result of experiments of topsoil particle saltation}

The experiment result of this study has converted the rotational speed of the fan at $1 \mathrm{~cm}$ wind speed from the ground. As shown in the Fig. 4 (a, b), the number of soil particles blown up when the wind speed at the ground surface is $5 \mathrm{~m} / \mathrm{s}$ is about $600-800\left(\mathrm{~N} / \mathrm{m}^{3}\right)$ at a particle size of $3 \mu \mathrm{m}$ and about $100\left(\mathrm{~N} / \mathrm{m}^{3}\right)$ at a particle size of $5 \mu \mathrm{m}$. The OPC value (the blown up soil particles number, $\mathrm{N} / \mathrm{m}^{3}$ ) has increased slowly from the point of wind speed is $5 \mathrm{~m} / \mathrm{s}$ (the rotation number is 1400) in the case of Wadi (DF and DF2) and from the point of wind speed is $7 \mathrm{~m} / \mathrm{s}$ (the rotation number is 1600) in Dry Lake beds. In terms of wind speed, $1400 \mathrm{rpm}$ is about $5 \mathrm{~m} / \mathrm{s}$ and 1600 is $7 \mathrm{~m} / \mathrm{s}$ at $1 \mathrm{~cm}$ from ground surface. In both $3 \mu \mathrm{m}$ and $5 \mu \mathrm{m}$, the amount of dust sharply increases from $7 \mathrm{~m} / \mathrm{s}(1600 \mathrm{rpm})$ in dry lake beds and Wadi.

According to the results from the field experiments of topsoil particles saltation, the soil particles on the ground surface in the Gobi desert area were emitted when the wind speed reaches $5 \mathrm{~m} / \mathrm{s}(1400 \mathrm{rpm})$, and the number of soil particles that are saltation increase abruptly at $7 \mathrm{~m} / \mathrm{s}$ $(1600 \mathrm{rpm})$. When the wind speed rises to $9 \mathrm{~m} / \mathrm{s}$ (1800 rpm), clearly a dust storm occurred. The critical wind speed at which dust emission on the ground surface is $7 \mathrm{~m} / \mathrm{s}$.

\subsection{Laboratory result of microorganisms adhering to the topsoil particles}

It is expected that these bacteria will fly at the time of dust generation, and Escherichia coli (DH $5 \alpha$ ) was used as a model of bacteria in this area to be domesticated grazed. Imaging of the sea sand attached with $E$. coli showed no remarkable fluorescence emission by fluorescence microscopy, but the observation of FE-
SEM clearly showed adherent of E. coli on the surface (see Fig. 5).
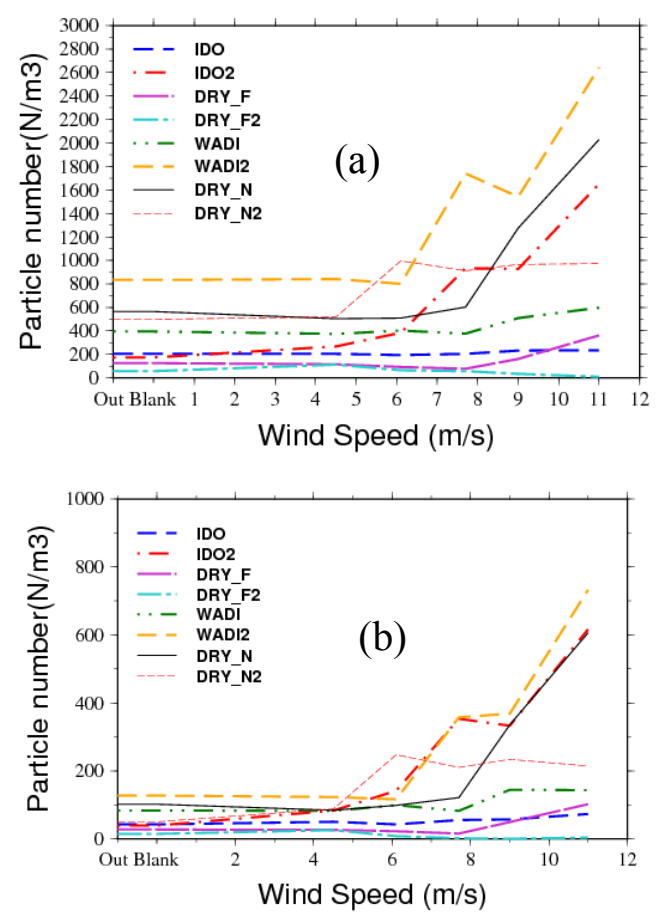

Fig. 4.The field experiment results of ground wind speed and OPT numbers of topsoil particles (Where, shows OPT setted particle size is (a) $3 \mu \mathrm{m}$ and (b) is $5 \mu \mathrm{m}$; the symbols in the figure shows: IDO-well; DF-dry lake beds; WD-Wadi).

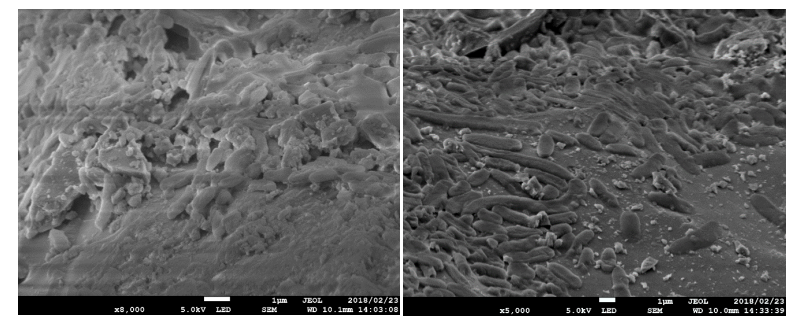

Fig. 5. (Left) shows the FE-SEM image of a UV irradiated sample in which $E$. coli was suspended together with sea sand and the (right) shows the FE-SEM image of an autoclaved sample suspended. The scale bars are $1 \mu \mathrm{m}$.

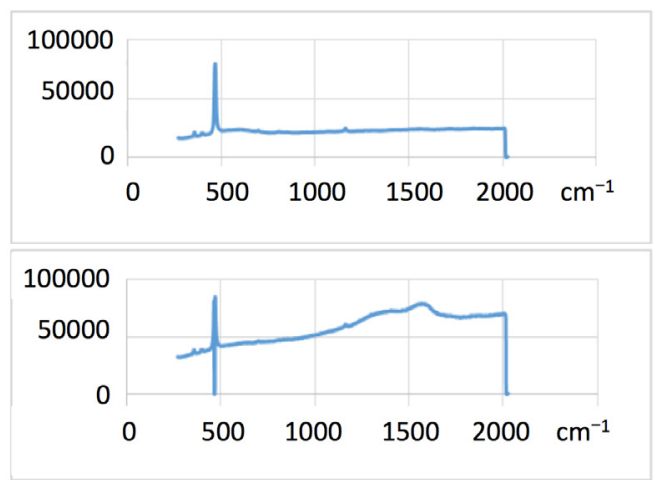

Fig. 6. Top panel: Spectrum of sea sand only; Bottom panel: Spectrum of sample which adsorbed $E$. coli on surface of sea sand. The y-axis is the Raman intensity in a. $u$. 
In Raman imaging, we could observe areas on the grains where the Raman spectra were different from the Raman spectrum of pure sea sand, but it is not clear whether this change is due to microorganisms. Fig. 6A shows the Raman spectrum of sea sand only; B shows the spectrum of a sample which adsorbed $E$. coli on the surface of sea sand. Two broad Raman peaks at around $400 \mathrm{~cm}^{-1}$ and $1600 \mathrm{~cm}^{-1}$ can be seen, which indicate organic material. Image of Mongolian soil particles were observed by fluorescence microscope and FE-SEM in Fig. 7. The fluorescence microscope images of Gobi desert soil of Mongolia country showed some fluorescing areas.

Observation of microorganisms adhered to the particles of the Gobi desert sample in Mongolia was only slightly binding, but from the observation of $E$. coli attaching the sample together with sea sand, we presume that the observation of attached microorganisms is, in principle, possible. However, because the control sample contained bacteria in a high number, and desert samples should contain just a few bacteria per grain of sand, we consider that it is difficult to observe them with FE-SEM at the present state. Using fluorescent-labelled bacteria would make it possible to first identify the bacteria in the fluorescence microscope and then image the same area in an FE-SEM.
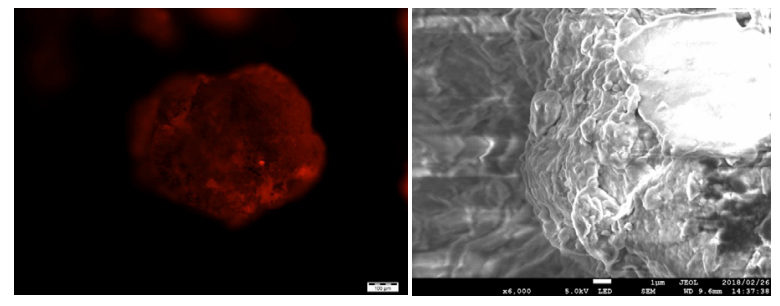

Fig. 7. Observation image of Mongolian soil particles with a fluorescence microscope (left, scale bar $=100 \mu \mathrm{m})$ and FESEM (right, scale bar $=1 \mu \mathrm{m}$ ).

\section{Conclusions}

The result of field experiment of soil particles saltation shows, in the critical wind speed when the dust emission on the ground surface of Gobi is $7 \mathrm{~m} / \mathrm{s}$. The result of laboratory experiment of imaging of microorganisms on topsoil particles collected from different landscape in the Gobi Desert shows, it is reported that bacteria are adhering to dust derived from Mongolia, but the adhesion efficiency may not be high. In Gramnegative bacteria like $E$. coli, there is a difference in adhesion to sand, but it may be necessary to study with different strains such as Gram-positive bacteria. The bacterial charge is also important when adhering to dust. It is inferred that the charge state of the dust component also affects the adhesion.

Since it was impossible to observe cells using samples this time, we will aim at future work to observe microorganisms attached to desert soil particles by locating conditions under which microorganisms are easy to observe, such as fluorescence-labelled samples.

Acknowledgments: This work was supported by JSPS KAKENHI Grant Numbers JP24340111, JP25550079, JP26281003 and also a part of this work was conducted in Chitose Institute of Science and Technology, supported by Nanotechnology Platform Program (Synthesis of Molecules and Materials) of the Ministry of Education, Culture, Sports, Science and Technology, Japan (MEXT).

\section{References}

1. L. Natsagdorj, D. Jugder, Y.S.Chung, “Analysis of dust storms observed in Mongolia during 19371999”, Atmospheric Environment, 37 (2003)

2. J. Huang, T. Wang, W. Wang, Z. Li, H. Yan, "Climate effects of dust aerosols over East Asian arid and semiarid regions", J. Geophys. Res. Atmos., 119 (2014)

3. Y. Sofue, B. Hoshino, Y. Demura, K. Kai, K. Baba, E. Nduati, A. Kondoh, T. Sternberg, "Satellite Monitoring of Vegetation Response to Precipitation and Dust Storm Outbreaks in Gobi Desert Regions", Land, 7 (2018)

4. Y. Sofue, B. Hoshino, E. Nduati, A. Kondoh, K. Kai, T. Purevsuren, K. Baba, "Remote sensing methodology for detection of environmental regime shifts in semi-arid region", In Proceedings of the 37 th Geoscience and Remote Sensing Symposium, Fort Worth, TX, USA, 5113-5116 (2017)

5. Y. Demura, B. Hoshino, K. Baba, C. McCarthy, Y. Sofue, K. Kai, T. Purevsuren, K. Hagiwara, J. Noda, "Determining the Frequency of Dry Lake Bed Formation in Semi-Arid Mongolia From Satellite Data", Land, 6 (2017)

6. Y. Demura, B. Hoshino, Y. Sofue, K. Kai, T. Purevsuren, K. Baba, J. Noda, "Estimates of ground surface characteristics for outbreaks of the Asian Dust Storms in the sources region", ProScience, 3 (2016)

7. J. Huang, T. Wang, W. Wang, Z. Li, H. Yan, "Accelerated dryland expansion under climate change", Nat. Clim. Chang, 6 (2016)

8. Y. Demura, B. Hoshino, Y. Sofue, K. Kenji et al., "Estimates of critical ground surface condition for Asian dust storm outbreak in Gobi desert region based on remotely sensed data," IEEE International Geoscience and Remote Sensing Symposium (IGARSS), 1 (2015)

9. L. Ashton, K. Lau, C. L. Winder, R. Goodacre, "Raman spectroscopy: lighting up the future of microbial identification", Future Microbiol., 6 (2011) 